\section{A configuração da reforma psiquiátrica em contexto local no Brasil: uma análise qualitativa}

\author{
Psychiatric reform in a local context in Brazil: \\ a qualitative analysis
}

\footnotetext{
${ }^{1}$ Faculdade de Ciências Médicas, Universidade Estadual de Campinas, Campinas, Brasil.

Correspondência M. S. Queiroz Faculdade de Ciências Médicas, Universidade Estadual de Campinas. Cidade Universitária Zeferino Vaz, C. P. 6166, Campinas, SP 13083-970, Brasil. msq44@uol.com.br
}

\begin{abstract}
This study focuses on the daily institutional activities in a Center for Psychosocial Care (CAPS), a municipal mental health service in Andradas, Minas Gerais, Brazil. The study specifically analyzes the social representations by health care professionals regarding the social rehabilitation of their patients, vis-à-vis new proposals approved under the Brazilian psychiatric reform. The study adopts a historical and conjunctural analysis, based on the premise that to evaluate the new process of institutional intervention contributes to both its implementation and improvement. The study also focuses on the stance by health care professionals towards interdisciplinary work and the factors involved in this practice. A qualitative approach was used throughout the study.
\end{abstract}

Mental Health; Deinstitutionalization; Health Personnel
Sônia Marina Martins de Oliveira Antunes 1 Marcos de Souza Queiroz 1

\section{Introdução}

Durante a segunda metade do século XX, a assistência psiquiátrica passou e vem passando por profundas mudanças nos países ocidentais, inclusive o Brasil. Tais mudanças culminaram na reforma psiquiátrica, que determinou o surgimento de um novo paradigma científico e novas práticas de assistência em saúde mental. Por ser um fenômeno recente no Brasil, que se manifesta no contexto descentralizado do Sistema Único de Saúde (SUS), a sua avaliação passa necessariamente por estudos qualitativos em nível local. Este trabalho é uma contribuição nesse sentido.

O objetivo principal desse artigo é avaliar o processo de desospitalização no interior da reforma psiquiátrica, conforme sua manifestação no Município de Andradas, Minas Gerais. Para isso, através de uma perspectiva qualitativa, analisamos as representações sociais dos profissionais de saúde do programa do Centro de Atenção Psicossocial (CAPS) desse município, sob os seguintes aspectos: as condições de trabalho, envolvendo o trabalho interdisciplinar; a eficácia do tratamento e os benefícios para o paciente; as dificuldades e obstáculos enfrentados no dia-adia; as críticas ao sistema de saúde e ao modelo de desospitalização. 


\section{O movimento da reforma psiquiátrica no Brasil}

O processo de reforma psiquiátrica inicia-se, nos anos 60, como um movimento contestador da perspectiva medicalizante da doença mental, envolvendo propostas alternativas em relação aos manicômios. O chamado movimento anti-psiquiátrico percorreu vários países, com o intuito de dissolver a barreira entre assistentes e assistidos; abolir a reclusão e repressão imposto ao paciente e promover a liberdade com responsabilidade dos pacientes. Tais propósitos incluíam, ainda, a prática de discussão em grupo, envolvendo uma postura essencialmente interdisciplinar 1 .

Ao enfatizar sua crítica aos pressupostos que sustentavam a instituição manicomial, Basaglia 2 demonstrou que o problema da doença mental está inserido no interior de uma temática política. A ênfase prática de sua proposta envolvia, basicamente, a diminuição de leitos nos hospitais psiquiátricos e o desenvolvimento de uma rede de serviços psiquiátricos na comunidade, composta por equipes interdisciplinares, capazes de responder às demandas dos pacientes e de seus familiares.

Tal perspectiva foi desenvolvida em oposição ao reducionismo positivista, que percebia o fenômeno da doença mental como um fenômeno que se manifesta meramente no nível biológico, em prejuízo das noções de ser, de existência e de integridade dos seres humanos 3 .

No Brasil, a criação do SUS, em sintonia com a constituição de 1988, preconiza a universalização do acesso aos serviços de saúde, a integralidade da atenção, a eqüidade e a hierarquização dos serviços, em um contexto descentralizado e municipalizado. Com mecanismos de descentralização e co-gestão em sua organização, o SUS contemplou em suas diretrizes os princípios da reforma psiquiátrica, incluindo o processo de desospitalização e a garantia dos direitos de cidadania dos doentes mentais 4,5 .

Assim como o SUS, a reforma psiquiátrica no Brasil consistiu em um processo que incluiu movimentos sociais e políticos, que desconstruíram tanto os conceitos de saúde em geral, como os de práticas em psiquiatria, em particular. O Projeto de Lei "Paulo Delgado" propõe, nesse sentido, a extinção progressiva do modelo psiquiátrico clássico, inclusive de hospitais especializados, com sua substituição por outras modalidades assistenciais 6 .

Após 12 anos de tramitação no Congresso Nacional, a Lei $n$. 10.216 foi finalmente sancionada pelo Presidente da República em 6 de abril de 2001, lei esta que dispõe sobre a proteção e os direitos das pessoas portadoras de transtornos mentais. A lei em questão proíbe, em todo o Brasil, a construção de novos hospitais psiquiátricos e a contratação pelo serviço público de leitos e unidades particulares deste tipo; estabelece que os tratamentos devem ser realizados, preferencialmente, em serviços comunitários de saúde mental e, como finalidade primordial, procura a reinserção social do doente mental em seu meio. A internação só será indicada quando os recursos extra-hospitalares se mostrarem insuficientes 5 .

Com o fenômeno da desospitalização, surgem novos serviços, denominados de CAPS e Hospitais-Dia. Tais serviços são caracterizados como estruturas intermediárias entre a internação integral e a vida comunitária; são impulsionados pelos projetos de reforma psiquiátrica, que vêm sendo implementados em grande parte dos Estados brasileiros.

Como resultado dessa nova política, o número de leitos em hospitais psiquiátricos vem apresentando um declínio contínuo no Brasil. Em 1996, o seu número era de 72.514, enquanto em 2002, projetava-se uma queda para 55.069. Simultaneamente à diminuição de leitos hospitalares, tem ocorrido a ampliação dos CAPS. Em 1996, havia 154 deles e, em 2002, projetavase um crescimento para 424 , representando um aumento da ordem de $175 \% 5$.

Ao finalizar este tópico, é importante trazer à tona alguns números sobre a dimensão do problema de saúde mental no Brasil. Segundo o Ministério da Saúde, a prevalência de transtornos mentais na população está em torno de $21,4 \%$. Tais transtornos ocorrem de acordo com a seguinte distribuição: os severos e persistentes, que necessitam de atendimento contínuo, estão em torno de $3 \%$; os graves, decorrentes do uso prejudicial de álcool e outras drogas, em torno de 6\%; os que necessitam de atendimento contínuo ou eventual correspondem a $12 \%$; os relacionados à epilepsia correspondem a $1,4 \%$ do total 5 .

O estudo empreendido por Costa 7 traz alguma luz sobre o significado dos gastos do SUS com problemas relacionados ao transtorno mental. Segundo este autor, este tipo de gasto ocupa o quarto lugar em relação aos gastos totais de internação do SUS, realizada principalmente em hospitais privados. Em 2000, o gasto do SUS com tal tipo de serviço consumiu cerca de 470 milhões de Reais em custos financeiros diretos, sem considerar as perdas que a internação representa, tanto em âmbito social como em âmbito da produção econômica. Apenas $10 \%$ desse montante são atribuídos a gastos com o modelo preconizado pela reforma psiquiátrica, o que representa o financiamento de 266 serviços substitutivos ao hospital psiquiátrico. Tais serviços foram criados nos últimos dez anos, mas ainda são insuficien- 
tes para o atendimento integral das necessidades da população.

\section{Referencial metodológico e o campo de pesquisa}

O conceito de representação social, adotado por esta pesquisa como categoria analítica, foi desenvolvido por Moscovici 8 . De acordo com este autor, tal conceito diz respeito ao fenômeno da comunicação psicológica e social de significados no espaço da vida cotidiana. Neste sentido, a realidade é entendida como uma construção tanto social como mental, dentro de um contexto de valores, noções, regras e normas pré-estabelecidas pela sociedade e pela cultura mais ampla.

O campo da presente investigação é o CAPS de Andradas. A instituição localiza-se em uma chácara dentro do perímetro urbano, ocupando uma área de $20.000 \mathrm{~m}^{2}$, oferecendo assistência, na ocasião da pesquisa, a 45 pacientes distribuídos em regime de um ou dois turnos, respeitando os parâmetros estabelecidos pelo SUS.

As modalidades de atendimento no CAPS constituem um universo de prática, que visa dar suporte ao paciente em crise, envolvendo não só o tratamento clínico, mas uma compreensão da situação que o circunda, com intervenções que têm por objetivo assegurar sua reinserção no contexto social e familiar. O CAPS é composto por uma equipe interdisciplinar (psiquiatras, assistentes sociais, psicólogos, terapeutas ocupacionais, auxiliares de enfermagem, monitores sociais). Na ocasião de nossa pesquisa, a equipe de saúde era representada por um médico psiquiatra, dois assistentes sociais, dois psicólogos, um terapeuta ocupacional, uma enfermeira, duas auxiliares de enfermagem e três monitores sociais. Destes profissionais, somente os auxiliares de enfermagem e os monitores sociais não possuíam nível universitário.

Utilizamos, nessa pesquisa, procedimentos metodológicos influenciados pela perspectiva etnográfica, sendo os principais instrumentos o método da observação participante e as técnicas de entrevistas semi-estruturadas. Sem seguir padrões rígidos ou pré-determinados, o pesquisador procurou desenvolver, no trabalho de campo, uma postura aberta, na qual a pesquisa se transforma em experiência vivencial.

As entrevistas foram direcionadas à totalidade de profissionais de saúde que compõem a equipe do CAPS. Todas as entrevistas, gravadas, foram realizadas individualmente no espaço do CAPS e, em média, duraram aproximadamente noventa minutos cada. A coleta de dados foi aplicada no período de junho a setembro de 2003.
O tratamento das entrevistas, após serem transcritas, foi feito de acordo com os princípios consagrados pela pesquisa qualitativa, que envolvem a extração de categorias, unidades de significado e análise, de acordo os procedimentos preconizados por Bardin ${ }^{9}$ e Martins \& Bicudo 10.

No que diz respeito à observação participante, ela ocorreu quase sempre nos momentos que antecederam e que sucederam as entrevistas, tendo em vista observar a prática profissional no dia-a-dia da instituição. Um diário de pesquisa foi elaborado com o propósito de coletar as impressões extraídas da experiência de pesquisa.

\section{Apresentação e análise dos dados}

\section{Concepções dos profissionais de saúde} sobre a doença mental: a influência do paradigma mecanicista nas representações dos profissionais de saúde

No interior de um novo paradigma e de uma nova prática de atenção à saúde, que envolve, concomitantemente, a desospitalização e a implementação de iniciativas para reinserir o paciente em seu meio social e familiar, o contato mais imediato da equipe de saúde com a realidade cotidiana do paciente tem se mostrado um fator crucial. É ela que permite a compreensão do fenômeno saúde-doença em termos ampliados e estabelece um limite à dimensão que define o processo saúde-doença em termos meramente biológicos. Nesse caso, o foco necessário para o diagnóstico, tratamento e cura abrange as dimensões emocional, familiar e social do paciente. Ao penetrar o modo de vida do paciente, a causa da doença mental torna-se complexa e passa a exigir uma aproximação interdisciplinar, como revelam os trechos de entrevistas abaixo.

“... As questões extrínsecas à doença, quer sejam questões individuais, ambientais ou sociais irão influenciar decisivamente tanto na sua evolução como no seu prognóstico; aí é que percebemos as limitações do modelo tradicional e a necessidade da realização prática, através de uma equipe interdisciplinar, das concepções teóricas sobre saúde mental" (Psiquiatra).

"Quando realizo visitas domiciliares, todo o prisma ambiental vivido pelo usuário doente mental surge com todas as suas cores e complexidades; é possivel então compreender porque determinado paciente não evolui satisfatoriamente. $O$ ambiente familiar negativo desempenha um papel preponderante nisso" (Assistente social).

Observamos em nossas entrevistas certo clamor para modificar a visão preconceituosa tra- 
dicionalmente aceita, inclusive por médicos e profissionais da saúde, que considera o doente mental como incapaz de socializar-se, incorporando-o em padrões de rejeição e isolamento. Há, nesse sentido, uma convicção generalizada de que a reinserção do paciente em seu meio familiar e social é uma condição fundamental para a sua cura. Esta postura percebe o tratamento e a cura como um processo que envolve não só a equipe de saúde, mas também o paciente e seu meio social e familiar. Há, entre nossos entrevistados, uma adesão total a esta perspectiva.

“... Temos observado que a reforma psiquiátrica se apresenta como um processo que vem crescendo, gerando novas discussões onde a sociedade também tem a sua responsabilidade, precisamos acreditar nisso" (Psicóloga).

“... Tentamos fazer o melhor para a aceitação da doença e o fim do preconceito. Eu não tenho dúvidas de que isso pode facilitar muito o tratamento e a cura do paciente" (Assistente social).

Ainda que pautadas por uma perspectiva que, em termos teóricos, propõe um novo paradigma científico para a área da saúde mental, no nível da intervenção prática, ainda ocorre significativa influência da perspectiva medicalizante anterior ao movimento da reforma psiquiátrica. Isso ocorre por dois motivos principais: a dificuldade de intervir nas condições de vida do paciente e os meios ainda insuficientes de que dispõem o CAPS.

Nesse sentido, observamos um aspecto comum a todas as entrevistas, que diz respeito tanto ao reconhecimento de que o envolvimento de aspectos afetivos, sociais e comunitários são fundamentais para a superação da doença, como o reconhecimento da dificuldade de implementar, na prática, procedimentos que possam dar conta da complexidade desta dimensão.

Ainda que toda a equipe tenha uma boa formação teórica da reforma psiquiátrica, os entrevistados demonstraram certa insegurança quando a questão focalizou a definição do fenômeno da doença mental. Quando solicitada em poucas palavras, esta raramente apareceu pronta. De um modo geral, houve a tendência de caracterizar a doença a partir de uma base organicista, embora a dimensão emocional também tivesse sido considerada.

“... Acho que poderia ser definida de várias maneiras. Pode ser um distúrbio mental de fundo hereditário, pode também ser relacionado a fatores emocionais. Enfim, existem vários conceitos ..." (Terapeuta ocupacional).

“... Entendo doença mental como um mau funcionamento do cérebro ...” (Monitor social).

“... Comparo a doença mental como um fato que pode acontecer como qualquer outra doença, por exemplo, o câncer ..." (Auxiliar de enfermagem).

Uma representação de ordem biológica e organicista da doença mental tende a produzir uma reificação do paciente, na medida em que elimina o contexto sócio-psicológico em torno do qual se formou o seu estado patológico 11. Nesse sentido, o processo saúde-doença tornase impregnado pelos preceitos que concebem a doença como o resultado da perturbação da regularidade e do equilíbrio biológico.

Desse modo, os profissionais entrevistados apontam que o exercício de suas práticas está baseado no diagnóstico psiquiátrico, com alusão às causas biológicas da doença mental. Assim, apesar de todas as tentativas e debates teóricos no sentido de se fomentar o trabalho multiprofissional, a prática ainda está impregnada pelo modelo tradicional, que busca a causa da doença, primariamente, na dimensão biológica e a cura através da intervenção medicamentosa.

Reforça esta atitude o comportamento dos usuários, que procuram o serviço com queixas específicas (sintomas) e buscam um alívio imediato para esta queixa (remédio que cura). A resistência às praticas terapêuticas mais demoradas, que envolvem uma atuação na dimensão emocional e social do paciente, é quase sempre muito grande.

“... Já ouvi o paciente dizer: a psicóloga não resolve nada - eu não vou ficar trabalhando de graça na oficina terapêutica, não estou vendo nenhum resultado. Eu quero um remédio que funcione para o meu problema" (Terapeuta ocupacional).

Em contraponto, e sustentando tais comportamentos, os profissionais da equipe multiprofissional sentem-se, por vezes, inseguros em promover tratamentos alternativos, não médicos, para a solução de alguns problemas de saúde mental. Esta insegurança, algumas vezes, acaba por se traduzir em uma atitude subordinada, dependente da consulta psiquiátrica. O produto final do trabalho multiprofissional, nesse contexto, desvaloriza-se, transformando-se em expressão de simples complemento do tratamento prescrito pelo psiquiatra. O sucesso ou insucesso do tratamento é, então, referendado ao êxito ou fracasso da conduta psiquiátrica, sendo que, nesse caso, a responsabilidade pesa desproporcionalmente sobre o profissional médico: “... $t i$ midamente observamos uma tentativa de trazer às queixas dos usuários questões outras que não o mero tratamento farmacológico" (Psiquiatra).

A questão da força que o antigo paradigma mecanicista da medicina mantém no contexto da reforma psiquiátrica do CAPS de Andradas mostra, ainda, um desdobramento no trabalho 
em equipe, no qual o médico psiquiatra detém um papel de hegemonia. Esta questão será tratada no tópico seguinte.

\section{Perspectiva interdisciplinar no} trabalho de equipe

O sentido da interdisciplinaridade reside na oposição à concepção de que o conhecimento se processa em campos fechados, em mundos particulares, isolados dos processos e contextos histórico-culturais. A proposta da reforma psiquiátrica, pelo contrário, conduz o profissional de saúde a novas práticas em saúde mental e abre perspectivas enriquecedoras envolvendo o trabalho interdisciplinar.

De um modo geral, o sentido interativo da interdisciplinaridade visa resgatar o diálogo entre o conhecimento humano e a realidade do mundo. O rompimento com a tradição e a abertura ao cotidiano, necessários para a manutenção deste diálogo, têm como referência negativa o reducionismo positivista o qual, em função de manter os formalismos e a quantificação nas ciências, prejudicou as noções de ser, de existência e integridade do saber humano ${ }^{3}$.

Observamos que os profissionais do CAPS procuram partilhar suas experiências e, com isso, desenvolver uma troca de informações entre as várias especialidades na busca de soluções para os problemas emergentes. Ao promover este sentido de diálogo, o trabalho interdisciplinar é explicitado pelos profissionais de saúde como a única forma de se conseguir um resultado efetivo no interior do objetivo proposto pela reforma psiquiátrica.

“... O lidar com a questão da doença mental extrapola as questões puramente médicas, psicológicas e sociais; a loucura deve ser avaliada dentro da sua própria multiplicidade e da sua interação com todos os aspectos da existência e do conhecimento" (Psiquiatra).

“... Eu entendo interdisciplinaridade como troca de informação e de experiência, o que requer trabalho com muita união, cada um na sua especificidade, mas também com o propósito de entender um pouco do trabalho do outro" (Terapeuta ocupacional).

“... Não tem jeito de você trabalhar sozinha numa equipe de saúde quando esta equipe se dispõe a prestar um serviço de qualidade ..." (Enfermeira).

“... Entendo que, num trabalho em equipe, é importante se sentir à vontade para discutir algum caso, trocar informações a respeito do quadro do paciente" (Psicóloga).

No ambiente de trabalho do CAPS, a busca de soluções para os problemas trazidos pelos pa- cientes é feita numa constante discussão entre os profissionais, o que demonstra uma forma prática de expressão do que seria uma forma de trabalho tipo colegiado. Considera-se que esta forma operacional permite vislumbrar o usuário por um prisma mais abrangente, e a atenção praticada faz-se de modo mais integral e dinâmico, mesmo que o prisma médico da questão "tratar sintomas" seja a prioridade.

É evidente que, neste contexto, em que o saber é construído e reconstruído constantemente em função de um determinado caso, as verdades produzidas são mais instáveis e provisórias. Como mencionado anteriormente, em tal ambiente, o recurso ao diagnóstico médico e às formas mais tradicionais de tratamento ocorre em várias ocasiões.

“... Percebo que algumas vezes a palavra final, a melhor maneira de prosseguir na intervenção, é a do médico ..." (Auxiliar de enfermagem).

Nas representações observadas, pudemos observar que as práticas buscam alcançar o ideal contido no novo paradigma da reforma psiquiátrica, mas esbarram nas dificuldades políticas, sociais e econômicas. Dentro de uma plêiade de condições cotidianas, os profissionais de saúde entrevistados reconhecem que a sua atuação deveria apreender as complexidades do adoecer psíquico, assim como os fatores que permeiam sua constituição dentro de um processo bio-psicossocial. Porém, a hegemonia do modelo médico tradicional sempre ocorre para os casos mais difíceis. Nesses casos, o papel do médico (com sua visão centrada na dimensão biológica) é considerado crucial para o tratamento, enquanto o papel dos demais profissionais da saúde (com sua visão centrada na dimensão psicológica e social) é considerado auxiliar ou complementar. O trecho da entrevista abaixo exprime bem a dominância e o poder simbólico do profissional médico.

“... Foi o psiquiatra que encabeçou todo o projeto na criação do CAPS, por isso ele usufrui uma grande credibilidade, tanto dos pacientes como da comunidade. A dominância que ele usufrui na equipe de trabalho nos deixa mais seguros também e isso, com certeza, favorece a reinserção social do paciente" (Terapeuta ocupacional).

Ainda que se processe com a dominância do profissional médico, a interdisciplinaridade é utilizada pelos profissionais de saúde do CAPS como condição necessária para estabelecer as conexões possíveis entre todas as áreas de conhecimento do serviço. Para os profissionais pesquisados, verificamos uma tendência de crescimento da perspectiva interdisciplinar, envolvendo tanto o respeito às especialidades como um ímpeto natural de estabelecimento de pontes 
que possibilitam o diálogo. É provável que a consolidação dessa prática possa trazer, em futuro próximo, um sistema mais igualitário, tipo colegiado, entre os profissionais que constituem a equipe de saúde.

\section{O papel do SUS e do profissional de saúde} na desospitalização do doente mental

O CAPS de Andradas reproduz, em nível local, as dificuldades do sistema de saúde brasileiro. Entre essas dificuldades, configura-se uma grande contradição entre o plano ideal e as condições efetivas de sua implantação. Tal tipo de contradição é consistente nas representações de nossos entrevistados, que procuram encontrar um responsável político pelo aperto financeiro e pelo precário apoio disponível: “... todos nós aqui sentimos uma falta danada de compromisso do setor público ..." (Assistente social).

Há um reconhecimento de que houve avanços na implementação de políticas públicas para a área de saúde mental nos últimos anos, mas a influência que estas produzem na realidade cotidiana é percebida como insuficiente, pela magnitude do problema e pelo isolamento de várias regiões do país, principalmente o seu interior distante das capitais e zonas metropolitanas.

“... Com muita lentidão, o sistema tem incorporado em suas políticas os novos conhecimentos; não tem sido um processo equânime em todo o Brasil, sendo que em algumas regiões o avanço é maior e em outras, menor ..." (Psiquiatra).

No que diz respeito ao processo de desospitalização, a maioria das representações manifesta um sentimento de frustração com o investimento governamental insuficiente para o setor. Nos trechos abaixo, observamos uma explicação política e econômica, bastante prevalente nas representações sociais dos entrevistados, o que é considerado um desestímulo ao seu trabalho.

"Há um discurso contraditório dos governantes e a atuação do SUS; percebo que gira em torno de questões políticas, com grande incompetência dos profissionais governantes" (Psiquiatra).

"Acho que para a desospitalização acontecer é preciso dar suporte aos municípios. Vejo que o movimento de reforma, com a própria desospitalização, o doente mental não foi o principal objetivo do movimento, mas a idéia principal era encontrar uma forma de amenizar o 'rombo' que havia nas finanças do Ministério da Saúde" (Psicóloga).

De acordo com Costa 7 os profissionais da saúde mental, ao mesmo tempo em que se ressentem da ausência de suporte governamental para com os objetivos das políticas públicas voltadas ao setor, advogam a necessidade de inter- locução e realimentação de suas experiências, reflexões e práticas. Tal situação é particularmente verdadeira quando os gestores da saúde em municípios brasileiros desprezam as políticas de saúde mental já estruturadas em nível federal. A autonomia do nível político local na gestão dos serviços de saúde permite aos municípios a inclusão precária, ou até mesmo a não inclusão, da reforma psiquiátrica na implementação das políticas públicas para o setor.

Os profissionais de saúde advertem que os investimentos governamentais insuficientes inviabilizam a inclusão de novas tecnologias como o treinamento voltado aos profissionais de saúde que atuam no contexto da reforma psiquiátrica. Todos os membros do CAPS entrevistados enfatizam a necessidade de mudanças significativas nas políticas públicas de saúde, a fim de permitir um maior compromisso, responsabilidade, solidariedade e ética no atendimento.

“... Precisamos investir em tecnologias humanas, e isso também custa dinheiro. Os profissionais precisam aprimorar seus conhecimentos, precisam de treinamentos, cursos, enfim precisam se sentir mais seguros e tranqüilos para intervir ..." (Assistente social)

"Percebo uma insensibilidade das autoridades governamentais para com a formação técnica e capacitação dos trabalhadores na composição de equipes de saúde mental. A equipe de saúde mental realiza um trabalho especialmente delicado e precisa estar adequadamente formada para tal. Poderíamos fazer muito melhor o que estamos fazendo" (Enfermeira).

Para a grande maioria dos nossos entrevistados, a maneira que o SUS investe no processo de desospitalização está intrinsecamente ligada às questões que envolvem o modo de produção capitalista, onde o sistema prioriza a quantificação e dificulta a qualidade da assistência, sob a ótica da produção e ampliação de capital.

“... Há grandes incoerências dos governantes: percebo que gira em torno de resistências políticas, a eterna crise econômica do país e o massacre que sofremos do FMI e do capital externo; as mudanças de rumo dos programas governamentais; a lerdeza ou os excessos na efetivação dos projetos ..." (Psiquiatra).

Tal ponto de vista é reforçado por vários autores, entre eles, Luis 12, que constata que o fator primordial da reforma psiquiátrica é o da produção de uma maior racionalidade econômica na área da saúde mental. Em tal contexto, a maior qualidade no tratamento médico dispensado aos pacientes torna-se um fator secundário.

Apesar das dificuldades inerentes à conjuntura econômica do país, para os profissionais entrevistados, a reforma psiquiátrica tem con- 
tribuído sobremaneira para os avanços relacionados às suas práticas profissionais. Verificamos, assim, que o CAPS de Andradas mostra-se com possibilidades reais de se tornar viável, sobretudo, porque os profissionais envolvidos acreditam nas mudanças que o CAPS pode proporcionar ao usuário rumo à construção de sua cidadania.

\section{Considerações finais}

Observamos, nesta pesquisa, que a equipe de saúde do CAPS de Andradas reconhece, teoricamente, a complexidade do adoecer psíquico, admitindo, nesse sentido, os fatores bio-psicossociais que permeiam sua constituição. Tal reconhecimento, no entanto, continua pressupondo a hegemonia do saber médico, que submete a equipe de saúde à sua lógica dominante e, com isso, enfraquece a dimensão cuidadora do programa.

A medicina pressupõe uma profissão que, historicamente, se beneficia de maior legitimação social, o que lhe confere um exercício de dominância em relação aos demais profissionais que formam uma equipe multidisciplinar de saúde. Tal dominância foi unanimemente reconhecida por nossos entrevistados.

Em um contexto de transição de uma ordem centrada no hospital para uma ordem centrada na família e no meio social do paciente, nem as regras estão bem constituídas, nem as práticas plenamente institucionalizadas. Com um apoio governamental insuficiente, o saber e a prática acumulados pela equipe de saúde tendem a ser interpretados e constituídos a partir de cada caso. Sem um lastro baseado no acúmulo de experiências e com pouco apoio institucional, é natural que, em tal circunstância, haja a tendência de recorrer ao velho paradigma médico centrado em uma perspectiva biologicista.

A própria visão cultural do paciente em relação ao novo modelo de desospitalização impede, por vezes, um exercício efetivo de ação interdisciplinar. Afastado de condições sociais que lhe proporcionariam maior cidadania, o paciente e seu meio sócio-familiar impõem, muitas vezes, considerável resistência quando a equipe de saúde tenta reintroduzir o usuário nas atividades cotidianas de sua comunidade.

A população, de um modo geral, ainda guarda preconceitos e temores em relação à loucura e, freqüentemente, não colabora com a proposta de assumir qualquer responsabilidade no tratamento e na reinserção familiar do paciente. Ainda que reconhecido pela equipe de saúde como fundamental para o exercício do novo paradigma, o trabalho multidisciplinar ainda apresenta pouco suporte. É importante mencionar que o médico da equipe de saúde é e tem sido o principal mentor da reforma psiquiátrica no interior da equipe de saúde CAPS. Se não fosse por este fator, dificilmente, tanto a reforma psiquiátrica como o trabalho interdisciplinar teriam condições de se sustentar no Município de Andradas.

Como principal obstáculo ao avanço da reforma psiquiátrica no contexto da nossa pesquisa encontra-se a perspectiva biologicista e hospitalocêntrica do paradigma mecanicista anteriormente hegemônico na área de saúde mental. Tal perspectiva ainda constitui um obstáculo principalmente porque ela ainda é partilhada, não só pelas classes populares, mas também pela classe dominante, envolvendo políticos, administradores e prefeitos que gerenciam o sistema de saúde. Tais classes, ainda percebem a doença mental como um problema a ser afastado, não importando muito a forma de fazê-lo.

A inexistência de um clima político/cultural favorável à implementação e instituição do CAPS, principalmente por parte das prefeituras locais, frustra de certo modo a equipe profissional encarregada de sua implementação. As nossas entrevistas revelam que todos os profissionais entrevistados consideram que poderiam atuar com mais competência se os recursos disponíveis fossem adequados. Há, nesse sentido, um descontentamento generalizado com relação às políticas sociais públicas voltadas para o setor de saúde mental. Há, ao mesmo tempo, uma convicção de que o fechamento dos hospitais psiquiátricos vem acompanhado da montagem de novos serviços extra-hospitalares com recursos insuficientes para funcionar corretamente.

Em relação ao papel do SUS, a equipe de saúde do CAPS ressente-se da ausência de um investimento governamental adequado para o município. Entre as carências observadas, mais do que a falta de pessoal especializado, estaria a ausência de treinamento desse pessoal, assim como a realimentação de suas experiências específicas.

De um modo geral, nossos entrevistados atribuíram à postura conservadora da esfera municipal uma parcela maior da culpa pela situação de isolamento do profissional de saúde mental. Tal atitude inclui, ao mesmo tempo, uma percepção de saúde centrada no aspecto biológico da doença, e um desprezo pela política de saúde mental já estruturada em nível federal.

Nesta situação, os entrevistados reconheceram que o setor mais prejudicado é o relacionado com o acompanhamento pós-alta, que procura a reinserção do paciente em sua família e na comunidade. Tal tipo de serviço, considerado fundamental, é praticamente inexistente no 
contexto de nossa pesquisa. Para implementá-lo, considerou-se indispensável, além da formação técnica e capacitação continuada dos profissionais envolvidos, um serviço de supervisão tanto das equipes como da situação do paciente. A possibilidade de realizar tal formação sempre esbarra na questão financeira.

Apesar dos obstáculos mencionados, percebemos que, no contexto do CAPS de Andradas, há uma tendência de crescimento da reforma psiquiátrica, em sentido mais amplo, e do trabalho interdisciplinar, em sentido mais estrito. Os profissionais entrevistados revelaram perceber positivamente o atendimento e as práticas interdisciplinares no interior do processo de desospitalização.

Percebemos também uma atitude por parte de cada especialista entrevistado no sentido de admitir os limites de sua especialidade para dar conta de um processo maior, que é o da saúde. Implícito em tal atitude encontra-se o entendimento de que um diálogo constante entre as especialidades é absolutamente necessário para dar conta da doença mental.

Desta forma, podemos afirmar que, de um modo geral, a equipe de saúde do CAPS esforça-se para superar os limites de suas atribuições específicas, tendo em vista promover a reabilitação e reinserção na comunidade do paciente. Verificamos, nesse sentido, uma unanimidade, entre os profissionais entrevistados, na avaliação de que os pacientes tratados a partir do processo de desospitalização têm sido amplamente beneficiados em relação aos pacientes tratados na forma hospitalar tradicional. Mesmo quando considerado o tratamento dispensado a pacientes do sistema privado, através de convênio médico, foi creditado ao programa CAPS um reconhecimento favorável.
Em suma, as representações sociais de nossos entrevistados sugerem que o atendimento realizado no CAPS de Andradas apresenta vários aspectos positivos em um contexto de várias dificuldades. Ficou evidente que os profissionais de saúde percebem o novo paradigma no campo da saúde mental como um avanço significativo no tratamento de indivíduos expostos a tais problemas, ainda que a sua implementação se faça com recursos insuficientes. A principal dificuldade apontada pelos entrevistados, nesse sentido, diz respeito à ausência de novas tecnologias para a área, as chamadas tecnologias humanas, que capacita e confere realimentação teórica à experiência dos profissionais.

A conseqüência inevitável da dificuldade apontada acima é que o trabalho em saúde mental tende a fragmentar-se e perder de vista a integralidade do cuidado, um aspecto que constitui a essência da reforma psiquiátrica. De certa forma, nossos entrevistados estão cientes desse fato, ao mesmo tempo em que procuram superar o problema através de uma postura voluntarista. $\mathrm{O}$ avanço da reforma psiquiátrica nesse contexto exige o apoio de uma política pública específica voltada para a promoção de um processo de trabalho integrado.

Podemos concluir nosso estudo afirmando que o desenvolvimento da reforma psiquiátrica no CAPS de Andradas requer um investimento maior na integração das equipes de trabalho, integração esta que necessita de um investimento específico no sentido de aprofundar a interação e o diálogo interdisciplinar. Faz parte deste aprofundamento a visão de que o conceito de saúde diz respeito a um fenômeno integral, que só pode ser acessível a um conjunto de especialidades em constante interação e diálogo.

\section{Resumo}

Este estudo focaliza o cotidiano institucional das atividades desenvolvidas pelo Centro de Atenção Psicossocial (CAPS), um serviço municipalizado de saúde mental em Andradas, Minas Gerais, Brasil. O estudo analisa, em particular, as representações sociais dos profissionais de saúde envolvidos com o atendimento do doente mental, face a sua reinserção social, frente às novas propostas preconizadas pela reforma psiquiátrica. Remete a uma análise histórica e conjuntural, partindo-se da hipótese de que avaliar o novo processo de intervenção institucional contribui para a sua implementação e aprimoramento. Focaliza tam- bém a postura dos profissionais de saúde, o trabalho interdisciplinar e os fatores que permeiam esta prática. Uma abordagem qualitativa é utilizada em toda a pesquisa.

Saúde Mental; Desinstitucionalização; Pessoal de Saúde

\section{Colaboradores}

O artigo foi escrito por ambos os autores. 


\section{Referências}

1. Rodinesco E. História da psicanálise na França: a batalha dos cem anos. Rio de Janeiro: Jorge Zahar Editor; 1986.

2. Basaglia F. A instituição negada. Rio de Janeiro: Edições Graal; 1985.

3. Morin E. Epistemologia da complexidade. In: Schnitman DF, organizador. Novos paradigmas, cultura e subjetividade. Rio de Janeiro: Editora Artes Médicas; 1996. p. 274-86.

4. Vasconcelos EM. Avaliação de serviços no contexto da desinstitucionalização psiquiátrica: revisão de metodologias e estratégias em pesquisa. J Bras Psiquiatr 1995; 44:189-97.

5. Coordenação Geral de Documentação e Informação, Ministério da Saúde. Legislação em saúde mental. Brasília: Ministério da Saúde; 2001.

6. Rotelli F, Amarante P. Reformas psiquiátricas na Itália e no Brasil: aspectos históricos e metodológicos. In: Bezerra Jr. B, Amarante P, organizadores. Psiquiatria sem hospício: contribuições ao estudo da reforma psiquiátrica. Rio de Janeiro: Editora Relume-Dumará; 1992. p. 41-55.
7. Costa ACF. Por uma transformação cultural. In: Anais da III Conferência Nacional de Saúde Mental. Brasília: Conselho Nacional de Saúde; 2001. p. 127-41.

8. Moscovici S. A representação social da psicanálise. Rio de Janeiro: Jorge Zahar Editor; 1978.

9. Bardin L. Análise de conteúdo. Lisboa: Edições 70; 1977.

10. Martins J, Bicudo MAV. Pesquisa qualitativa em psicologia: fundamentos e recursos básicos. São Paulo: Educ/Editora Moraes; 1989.

11. Perrusi A. Imagens da loucura: representação social da doença mental na psiquiatria. São Paulo: Cortez Editora; 1995.

12. Luis MAV. A respeito da exclusão: instituição asilar e desinstitucionalização. In: Jorge MSB, Silva WV, Oliveira FB, organizadores. Saúde mental: da prática psiquiátrica asilar ao terceiro milênio. São Paulo: Lemos Editorial; 2000. p. 78-101.

Recebido em 20/Out/2005

Versão final reapresentada em 02/Mai/2006 Aprovado em 26/Mai/2006 